\title{
Sobre a varíola e as práticas da vacinação em Minas Gerais (Brasil) no século XIX
}

\author{
About smallpox and vaccination practices in Minas Gerais \\ (Brazil) in the $19^{\text {th }}$ century
}

Anny Jackeline Torres Silveira ${ }^{1}$

Rita de Cássia Marques ${ }^{2}$

${ }^{1}$ Colégio Técnico da Universidade Federal de Minas Gerais . Av.

Presidente Antônio Carlos 6.627, Pampulha. 31270901 Belo Horizonte MG. anejack@terra.com.br ${ }^{2}$ Escola de Enfermagem, Universidade Federal de Minas Gerais.
Abstract This article discusses the impact of smallpox and vaccination practices used against the disease used in the province of Minas Gerais, in Brazil, during the Imperial Period (1822-1889). Despite the existence of services responsible for the organization and dissemination of the vaccine in the country since the early 19th century, some administrative and cultural factors, as identified in documents produced by the province's public health authorities at the time, had a negative impact upon the full implementation of both practice and organization of services aimed at the dissemination of smallpox vaccination. Based upon historiographic sources, it is argued that despite the trend towards centralization observed at different governmental spheres during the structuring of the Imperial State, in particular, in the provision of vaccination services, there was a prevailing disharmony between the different agencies responsible for the implementation and management of such services. A further contributor to the difficulties in the service implementation was the resistance of the population to submit to the vaccination, a phenomenon that can be best understood through examination of the social construction of perceptions about diseases and the vaccination method used against the smallpox. Key words Smallpox, Vaccination, Public Health, History of Minas Gerais, Brazil Empire
Resumo Este artigo analisa o impacto da variola e da prática da vacinação antivariólica em Minas Gerais durante o período imperial brasileiro (1822-1889). Apesar da presença de órgãos que visavam à organização e à propagação da vacina no país desde o início do século XIX, identifica-se, pela documentação relativa à saúde pública produzida pelas autoridades provinciais, uma série de fatores de natureza administrativa e cultural que influenciaram negativamente na plena implementação quer da vacina quer da estrutura organizada no período visando à sua difusão. Seguindo as proposições da historiografia dedicada ao tema, discute-se que, apesar da tendência à centralização observada em diferentes esferas da administração no processo de estruturação do Estado Imperial, no âmbito da saúde e, particularmente, no âmbito do serviço de vacinação antivariólica, prevaleceu uma desarticulação entre os diferentes agentes responsáveis pela implementação e o controle desse serviço. Outro aspecto que contribuiu para as dificuldades relativas à implementação desse serviço foi a grande resistência da população em submeter-se à vacina e que pode ser entendida pela análise das percepções sociais construídas sobre a doença e o método da vacinação. Palavras-chave Varíola, Vacinação, Saúde Pública, História de Minas Gerais, Brasil Império 


\section{Introdução}

A ausência de vetores intermediários e a necessidade da transmissão direta para que possa persistir fizeram da varíola uma doença característica das sociedades sedentárias. A origem da moléstia permanece um enigma. Alguns autores sugerem sua presença desde a Antiguidade, em assentamentos agrícolas dos vales fluviais no Egito, na Índia e na China ${ }^{1}$. Entretanto, a falta de descrições claras sobre os sintomas dessas afecções impõe limites para um diagnóstico confiável ${ }^{2}$. Acredita-se que, antes mesmo do final do primeiro milênio, a varíola prevalecesse em sua forma epidêmica em regiões de alta densidade populacional da Europa e da Ásia, atingindo áreas periféricas como a África Subsaariana e o norte europeu.

Discutindo a história da doença, Dobson ${ }^{1} \mathrm{diz}$ que durante o século XVI a varíola representava cerca de dez a quinze por cento da taxa de mortalidade, atingindo indistintamente príncipes e camponeses. A maior parte de suas vítimas encontrava-se entre crianças abaixo de dez anos, mas os adultos não estavam imunes aos seus ataques. Entre vinte a quarenta por cento dos infectados morriam, e os sobreviventes, muitas vezes, carregavam os sinais de sua passagem na cegueira ou nas cicatrizes que cobriam e desfiguravam o corpo, especialmente a face. Nos séculos seguintes, a varíola se tornaria endêmica nas grandes cidades, e as povoações menores seriam alvo frequente de epidemias mais ou menos severas da moléstia ${ }^{1}$.

$\mathrm{Na}$ América, a doença é considerada uma das piores heranças dos colonizadores. Estudioso do impacto do expansionismo europeu na época moderna, Crosby ${ }^{2}$ afirma que a varíola teria cruzado o Atlântico no final de 1518 ou início de 1519, e durante os quatro séculos seguintes desempenhou um papel tão essencial quanto a pólvora no avanço do imperialismo branco do ultramar ${ }^{3}$. $\mathrm{O}$ isolamento do continente teria contribuído para a ausência de imunidade à varíola entre os nativos, explicando assim a rapidez de sua expansão e a alta taxa de mortalidade atribuída à doença tão logo iniciados os contatos com os colonizadores ${ }^{1,4,5}$. Mais tarde a doença foi associada ao tráfico de escravos, com o aumento de epidemias após a entrada de africanos.

No Brasil, as primeiras referências à varíola remetem ao primeiro século da colonização. Em 1561, a doença teria chegado à Bahia através de uma nau que trazia bexiguentos a bordo e, dois anos mais tarde, "toda a população litorânea foi assolada pela mais impressionante epidemia do século XVI no Brasil” " ${ }^{6}$. A doença teria feito cerca de 30.000 vítimas na Bahia, propagando-se para as capitanias de Pernambuco e de Piratininga, onde, em 1565, teria assumido uma grave forma clínica, assemelhando-se, pela confluência e odor das pústulas, à própria lepra ${ }^{7}$. Desse período em diante, o país conheceu epidemias devastadoras e de funestas consequências ${ }^{8}$. A doença teria sido ainda objeto do primeiro livro escrito sobre a medicina no país: o Tratado Único das Bexigas e Sarampo, de Simão Pinheiro Mourão, publicado em Lisboa em $1683^{7}$.

Entre as diferentes doenças que incidiram sobre a província de Minas Gerais durante o século XIX, nenhuma foi tão persistente e alcançou tanta proeminência como a varíola. As chamadas "bexigas” são uma referência constante nas correspondências encaminhadas ao governo mineiro pelas câmaras municipais, assim como nos relatórios e mensagens produzidos pelas autoridades provinciais durante todo o período imperial, como mostra o relatório do presidente Pedro de Alcântara Cerqueira Leite, do ano de 1865: De todas as epidemias que costumam nos afligir, a da variola é a que mais estragos faz, não só pela própria gravidade, como ainda mais pelo terror que infunde na população. Infelizmente temos todos os anos povoações invadidas por este mal, que nos vem da Corte, ou de outros lugares da Província de São Paulo, onde ela reina quase endemicamente ${ }^{9}$

Neste texto analisamos o impacto da varíola e da prática da vacinação antivariólica em Minas Gerais, durante o período imperial brasileiro. Ainda que se considere a existência de órgãos que visavam à organização e à propagação da vacina no país desde o início do século XIX, como a Junta Vacínica da Corte, criada em $1811^{10}$, a documentação relativa à saúde pública produzida pelas autoridades provinciais permite identificar uma série de fatores de natureza administrativa e cultural que influenciaram negativamente na plena implementação quer da vacina quer da estrutura que foi organizada durante o período visando à sua difusão. No caso da varíola, nem mesmo a reorganização dos serviços de vacinação através da criação do Instituto Vacínico (1846) conseguiu superar esses obstáculos. Vale ressaltar que a extinção do Instituto Vacínico e a incorporação de suas atribuições pela Inspetoria de Saúde - criada em 1886 em substituição à Junta de Higiene Pública - levaram a uma desestruturação ainda maior dos "parcos” serviços de vacinação ${ }^{10}$. Seguindo as proposições de alguns estudiosos sobre o tema ${ }^{10,11}$, discutimos a ideia de que, apesar da tendência à centralização obser- 
vada em diferentes esferas da administração no processo de estruturação do Estado Imperial, no âmbito da saúde e, particularmente, no âmbito do serviço de vacinação antivariólica prevaleceu uma desarticulação entre os diferentes agentes responsáveis pela implementação e o controle desse serviço. Os problemas enfrentados pelo serviço de vacinação podem ser entendidos ainda pela análise das percepções sociais construídas em torno da doença e da prática da vacina, resultando numa grande resistência da população em submeter-se a esse método de prevenção contra a varíola.

\section{A varíola em Minas Gerais}

A presença de um clima ameno e salubre, tão "acomodado à existência humana”, é retórica comum nos relatórios e mensagens presidenciais enviados Assembleia de Minas Gerais durante o Império $^{12}$. Entretanto, esses documentos também revelam uma infinidade de moléstias que atacavam a população mineira, como sarampo, coqueluche, escarlatina, beribéri, diarreias, gastralgias, hidropsia, reumatismos, pleurisias, bócio, sífilis, morfeia, opilação, tuberculose e diferentes qualidades de febres. Porém, à exceção do cólera, nenhuma doença mobilizou tantos esforços e atenção no correr do século XIX como a varíola. As manifestações da moléstia nesse período variaram bastante na sua intensidade. Várias das menções feitas à varíola resumiam-se a uma pequena notícia, dando conta de sua presença em determinada localidade, apontando ter a doença uma propagação restrita, com poucas pessoas atingidas e, às vezes, nenhuma vítima. Episódios dessa natureza são referidos na documentação como manifestações "benignas" da doença. Em outras ocasiões, porém, a varíola assumia um caráter mais agressivo, expandindo-se por diversas regiões num mesmo período, como se observou nos anos de 1873-1874, quando a doença atingiu várias cidades mineiras.

A primeira notícia sobre essa epidemia, feita na cidade de Ouro Preto em setembro de 1873, informava que um soldado do corpo policial da capital havia manifestado a doença, sendo então encaminhado para o isolamento. Apesar dessa medida, o contágio não pôde ser evitado, e em outubro e novembro a varíola expandiu-se entre os moradores da capital. A doença pareceu não tomar "proporções assustadoras", apresentando mesmo um declínio em dezembro, levando as autoridades ao julgamento de que em breve de- sapareceria $^{13}$. Contrariando essa previsão, a varíola permaneceu nos meses seguintes, recrudescendo em março e atingindo maior intensidade em junho. Os casos da moléstia continuaram sendo registrados na capital até o início de março de 1875, alcançando a cifra de 789 infectados e 204 mortos $^{14}$.

Essa manifestação da varíola avançou por outras localidades da província em 1874-1875. Em Juiz de Fora, de setembro de 1874 a fevereiro de 1875, a doença infectou cerca de mil pessoas, fazendo 135 mortos $^{13}$. Em Mariana, as autoridades estimaram 537 infectados e, entre eles, 161 faleci$\operatorname{dos}^{14}$. Em alguns lugares a epidemia teve um impacto mais expressivo, como no povoado do Inficcionado, cidade de Mariana, onde em uma população pouco superior a trezentos indivíduos houve 125 infectados, dos quais vinte faleceram ${ }^{13}$. Em Lavras, a freguesia de Carmo da Cachoeira registrou duzentos mortos, cifra considerada pelas autoridades uma "mortalidade espantosa", em uma população calculada em 5.410 pessoas $^{13}$. O balanço da epidemia divulgado pelas autoridades da província dava conta de que entre os 71 municípios que integravam o território de Minas no período em exame, 31 haviam acusado a presença da doença ao Inspetor de Saúde Provincial ${ }^{15}$.

As apariçõos da varíola são mencionadas em praticamente todos os relatórios anuais do governo provincial. A presença constante e difusa da moléstia e as limitações das teorias médicas prevalentes no período faziam desses recrudescimentos um verdadeiro mistério. A alternância entre manifestações "benignas”, em geral mais circunscritas e apresentando uma letalidade reduzida, e as aparições mais violentas como a de 1873-1874, então chamadas de "bexigas bravas", é explicada pelas proposições da virologia. Os estudos em torno da doença estabelecem a existência de dois tipos de varíola: a varíola major, que apresenta uma taxa de mortalidade elevada, atingindo de $25 \%$ a $30 \%$ dos infectados, e a varíola minor, com sintomas mais brandos e uma taxa de mortalidade de $1 \%$ ou menos ${ }^{2}$.

Benigna ou não, as manifestações da varíola despertavam verdadeiro pavor na sociedade mineira. São inúmeros os relatos sobre o abandono das áreas infectadas tão logo reconhecida a presença da doença. No povoado do Inficcionado, cerca de cinquenta pessoas haviam deixado a localidade durante a epidemia de 1873-1875, o que perfazia um sexto de uma população de trezentas almas ${ }^{16}$. Algumas vezes a fuga antecipavase à própria instalação da doença, como ocorreu em Arassuaí no ano de 1878, de onde as autori- 
dades informavam sobre a tormenta provocada pela notícia da existência da varíola em um arraial vizinho à cidade: reina a maior consternação $e$ o pânico é tal, que num só dia mais de 300 pessoas abandonaram seus lares, espavoridas e aterradas à presença da medonha moléstia ${ }^{17}$. Em 1874, o terror à doença afastou os deputados provinciais das reuniões anuais da Assembleia realizadas em Ouro Preto ${ }^{13}$. Reações dessa natureza levavam a consequências mais funestas, afastando as pessoas dos doentes, impossibilitando os cuidados exigidos pela recuperação, assim como das localidades contaminadas, interferindo no abastecimento e no comércio, tão necessários em quadra epidêmica. Em 1859, foram os fazendeiros e comerciantes que desaparecem da capital mineira, fazendo recrudescer a carestia de gêneros, por causa dos boatos que circulavam sobre a presença da varíola na cidade ${ }^{18}$.

O temor despertado pela varíola admite diferentes hipóteses. A proximidade da morte ou do desamparo, a perda dos entes queridos e as deformidades repulsivas eram alguns dos fatores que alimentavam o pavor despertado pela moléstia. A imposição do isolamento e da quarentena infligida aos doentes e aos lugares infectados por doenças contagiosas era outra importante justificativa desse medo provocado pela varíola. A possibilidade de ser privado de recursos básicos para a sobrevivência ou da mobilidade necessária para provê-los e a suspensão de práticas que ordenavam o cotidiano, fossem elas rituais ou não, eram certamente avaliadas de forma negativa pela população. Esse medo à doença pode ainda ter sido amplificado pelos temores despertados pela prática da vacinação, avaliada de forma negativa quanto à sua eficácia e vista como meio de propagação da varíola e de outras moléstias, além de ser percebida como uma forma de ingerência e de controle sobre a vida privada da população ${ }^{1}$.

Segundo Fernandes, a varíola ocupou um "lugar de expressão no quadro epidemiológico mundial" ${ }^{10}$ tanto pela forma indiscriminada e violenta de sua propagação como pelas marcas físicas indeléveis que deixava em suas vítimas. A doença caracterizava-se por um estado infeccioso cuja incubação durava cerca de 12 dias. A partir de então o indivíduo era abruptamente tomado por febre alta e fortes dores de cabeça, nas costas e nos músculos; as crianças apresentavam vômitos e convulsões. Nas infecções mais severas, o doente podia manifestar hemorragias na pele, nos pulmões e em outros órgãos, que levavam à morte antes mesmo do aparecimento das primeiras pústulas. Entre dois e cinco dias após manifestados os primeiros sintomas, apareciam pequenas erupções, especialmente na face, mãos e pés, que se transformavam em bolhas purulentas. Em casos extremos, as feridas confluíam, indicando uma infecção de caráter letal. No curso normal da doença, cerca de oito dias depois as pústulas ressecavam, formando crostas que, mais tarde, dariam lugar a cicatrizes características. Outras sequelas possíveis eram a cegueira e a infertilidade masculina ${ }^{2}$.

\section{O serviço de vacinação e os obstáculos a sua propagação na província}

Apesar do temor gerado por suas epidemias, a varíola era a única doença que contava com uma prática de controle imunitário estabelecida - a vacinação. Surgida em fins do século XVIII, a vacina jenneriana, ou vacina humanizada, era propagada através de uma "verdadeira cadeia de inoculações", transferindo-se de pessoa a pessoa a partir do cowpox da vaca ${ }^{10}$. Anterior à vacina, havia o método da variolização, que consistia na remoção de material das pústulas ou de suas crostas e sua inoculação em pessoas sãs ${ }^{1}$. No Brasil, essa prática, por muitos considerada herança dos escravos africanos, parece ter sido bastante difundida entre a população ${ }^{11}$.

A difusão da prática da vacinação no país remonta ao início do século XIX, sendo feita através da iniciativa de particulares ${ }^{11}$. Em Minas, o primeiro relato sobre a vacina data de 1805 . Em carta de 11 de novembro daquele ano, o governador da capitania mencionava a ordem régia solicitando às autoridades coloniais o empenho por todos os meios possíveis na familiarização da vacina entre os habitantes das capitanias: Soube felizmente que a vacina tem sido transportada para a Bahia e que pela vigilância e zelo do Vice-Rei do Estado a tinha feito conduzir para o Rio de Janeiro onde a mandei buscar, e a pude introduzir felizmente nessa capitania com o melhor sucesso, podendo segurar a V. Excia. que o numerário de vacinados de toda a idade e sexo nas comarcas desta capitania excede o de 3 mil pessoas e que virá a ser muito maior, uma vez que esse continue a aplicar ${ }^{19}$.

Em 1811, o Príncipe Regente criava na capital do Império a Junta Vacínica da Corte. O novo órgão ficava encarregado da propagação e conservação da vacina no Rio de Janeiro e nas demais províncias. Fernandes ${ }^{10}$ observa que a criação de um órgão específico para a propagação da vacina seguia a orientação verificada em ou- 
tros países, sendo justificada pela importância social e econômica assumida pela moléstia no período. Entretanto, avalia que a atuação da Junta foi irregular e pouco expressiva, e a propagação da vacina, muitas vezes, uma ação de caráter privado. Os dados levantados para Minas Gerais corroboram essa avaliação. As referências à vacina e à organização de sua propagação são muito mais frequentes a partir da segunda metade do século, após a criação do Instituto Vacínico do Império (1846) e da Junta de Higiene Pública (1850). Vale ressaltar, porém, que o aumento de referências à saúde ou à organização do serviço de vacinação na documentação oficial não pressupõe que eles tenham se tornado mais eficazes. Pelo contrário, tais referências expunham de forma mais clara as diversas dificuldades enfrentadas na administração da saúde na província.

Com a reformulação das câmaras municipais pela Lei de $1^{\circ}$ de outubro de $1828^{20}$, as responsabilidades relativas à saúde pública, antes sob a jurisdição do provedor-mor e do físicomor, foram transferidas para esses órgãos administrativos. Entre as atribuições sob a alçada municipal, estava a propagação da vacina que deveria ser conduzida pelo médico ou cirurgião do Partido da Câmara. A vacina era praticada nas igrejas, no edifício da Câmara ou nas fazendas espalhadas pelos municípios. A aplicação era anunciada através de edital, como este, publicado pela câmara de Mariana, em junho de 1830: Bernardo Pinto Monteiro, cidadão brasileiro e fiscal da Câmara Municipal desta leal Cidade de Mariana [...] The(s) faço saber que a Ilma. Câmara pôs em execução o artigo 69 da lei de $1^{\circ}$ de outubro de 1828, para que sejam vacinad(a)s todas as pessoas, tanto meninos como adultos, e assim devem concorrer a essa casa da Câmara, principiando no dia 14 do corrente mês, desde ás 9 horas às 11, que onde achar pronto o cirurgião-mor, José Luiz de Brito, presente o secretário para os tomar aval, onde também o serei presente, e durará aqueles dias que forem precisos e nas horas já marcadas de cada dia. A Ilma. Câmara espera que as operem para um ato tão útil para os brasileiros porque os livra infalível do seu inimigo geral, qual é a bexiga maligna. E para que chegue à notícia de todos, este será publicado pelo porteiro do auditório e afixado no lugar do costume $e^{21}$.

Em 1846, a Junta Vacínica foi substituída pelo Instituto Vacínico do Império, sendo incorporada neste como órgão consultor e responsável pela vacinação no município da $\operatorname{Corte}^{10}$. A criação do Instituto redefinia o serviço de vacinação na corte e organizava sua propagação no restante do Im- pério. Além da normatização e fiscalização da atividade de propagação da vacina, o novo órgão ficava responsável pela condução dos debates em torno da técnica e da distribuição da linfa. Nas províncias, a aplicação da vacina ficava a cargo do comissário vacinador provincial e dos comissários vacinadores municipais e paroquiais ${ }^{22}$.

Segundo o regulamento do Instituto, o comissário vacinador provincial deveria ser preferencialmente médico ou cirurgião, nomeado por ato legislativo provincial. Além de indicar e fiscalizar a atuação dos vacinadores municipais e paroquiais, o comissário provincial ficava responsável por encaminhar as solicitações da linfa ao Instituto Vacínico e remetê-las aos municípios; notificar às autoridades do Império a presença de qualquer epidemia de varíola; examinar a vacina de recrutas; encaminhar semestralmente ao Instituto uma exposição sobre as ocorrências "notáveis" e um mapa de vacinados. Por fim, devia praticar a vacina todos os domingos, além de em outro dia da semana, a todos que a buscassem, distribuindo certificados àqueles que tivessem aproveitado a vacina.

O cargo de comissário vacinador municipal, nomeado por portaria ministerial, deveria ser exercido pelo médico ou cirurgião de Partido da Câmara ou por aqueles que fossem encarregados pela propagação da vacina por ato legislativo provincial. Competia a ele as mesmas atribuições do comissário provincial, a quem devia manter informado sobre qualquer notícia relativa à varíola e à vacina. A função não era remunerada, mas previa-se essa possibilidade após dez anos de serviços prestados com o reconhecido zelo. A propagação da vacina nas povoações e freguesias era atribuição do comissário paroquial, cargo que, na ausência de um facultativo, poderia ser ocupado "por qualquer pessoa inteligente que se queira prestar a esse serviço" 22 . A possibilidade de remuneração seguia as determinações estabelecidas para o comissário municipal, havendo a dispensa de serviço da Guarda Nacional enquanto desempenhasse as funções de vacinador. Apesar das prescrições da lei, a documentação revela que, diante do reduzido número de médicos e boticários existentes na província durante o século XIX, frequentemente o governo via-se forçado a recorrer aos filantropos, ilustrados ou curiosos, no provimento desses cargos.

Como avalia Fernandes, a reforma efetuada no serviço de vacinação em 1846 seguia os "parâmetros político-administrativos" estabelecidos no período do Segundo Reinado, que determinavam “a centralização dos serviços nas mãos do gover- 
no imperial e atribuindo às localidades a responsabilidade pela execução e financiamento desses serviços" ${ }^{10}$. Porém, a intenção centralizadora expressa na reformulação desse serviço não levou a uma atuação mais eficiente ou a um maior controle em torno da prática. Ofícios e cartas trocados entre os comissários municipais e paroquiais e o provedor de saúde provincial apontam a existência de enormes dificuldades na implementação das disposições relativas à vacina, que iam dos problemas enfrentados na nomeação de comissários paroquiais até a qualidade das remessas da linfa encaminhadas pelo Instituto Vacínico, comprometendo a credibilidade da vacina.

As notícias sobre a aplicação da vacina antivariólica em Minas Gerais são escassas para o período anterior ao ano de 1840, o que corrobora a sugestão de que a atuação da Junta Vacínica foi pouco expressiva na propagação dela nos mais de trinta anos de existência ${ }^{10}$. A partir daquela década, porém, as informações se avolumam - movimento que, como sugerimos, guarda relação com as mudanças verificadas no próprio serviço de vacinação (1846) como na reorganização dos serviços de saúde efetivada com a criação da Junta de Higiene (1850), mas que não significou necessariamente maior eficiência no trato das autoridades com as questões relativas à saúde. Entre a documentação surgem então incontáveis relatos afirmando não ter a vacina produzido os efeitos esperados - qual seja, o surgimento de pústulas das quais se retirava material para a propagação dela. Eram muitas as explicações para o fenômeno: a corrupção da linfa pelos calores do trópico; a demora no transporte das amostras, fazendo com que a vacina ficasse fraca ou velha; a danificação do material encaminhado - lâminas e tubos capilares - que chegava ao comissário em "estado verdadeiramente inútil" 23 .

Havia solicitações não respondidas pelas autoridades e localidades nas quais nunca houve um único vacinador. Situações como essas resultavam na desarticulação e na descrença em relação à prática, como mostra correspondência assinada por um médico da cidade de Sabará, no ano de 1847: Dentro e fora desta a cidade queixam-se alguns chefes de famílias, que vacinam os seus todas as ocasiões que por aqui aparece vacina, e raramente obtêm que uma ou outra pessoa tenha uma vesícula, e isto depois de reiteradas tentativas Daí vem que muitos já deixaram de procurar este meio, que único até hoje, tem salvado muitas vidas e guardado, [...] destas deformidades repulsivas, milhares de semblantes ${ }^{24}$.
Outro obstáculo na estruturação do serviço de vacinação era a ausência ou o desinteresse dos vacinadores designados para os municípios e paróquias. A documentação é farta em menções sobre a vacância de cargos por mudança ou falecimento dos indicados, há três, quatro, sete anos, como mostra essa carta enviada em 1869 da cidade de Curvelo informando às autoridades que há seis anos o Dr. José Candido Coutinho da Ferreira deixou de residir no termo, indo estabelecerse no Pará e que, apesar disso, o Comissário Provincial ainda lhe envia correspondência destinada a ele, como se ainda fosse Vacinador Paroquial25. Há também inúmeras solicitações de exoneração da função, justificadas por outros cargos já assumidos, os afazeres cotidianos, a mudança de residência, a existência de médicos na cidade que poderiam conduzir a atividade com mais proveito, problemas de saúde ou de ordem familiar, entre outros. As dificuldades e a precariedade na organização do serviço de vacinação podem ser avaliadas pelos informes oficiais dando conta que em 1869 havia na província 196 lugares designados de comissários vacinadores, achando-se ainda 373 a serem preenchidos ${ }^{26}$.

O controle e a sistematização da prática da vacinação ainda eram prejudicados pela existência de comissários que, apesar de nomeados, não desempenhavam a função. Chama a atenção a ingerência de autoridades municipais na organização do serviço, como o caso do Juiz de Órfãos de Ayuruoca, que dizia ter distribuído a linfa entre outros cidadãos por não confiar nos vacinadores indicados ${ }^{27}$. No relatório encaminhado ao Presidente da Província em 1869, o provedor de saúde reclamava o fato de não ter aquela repartição nenhuma força para fazer cumprir suas obrigações àqueles que deviam prestar-lhe trimestralmente circunstanciadas informações de suas respectivas localidades ${ }^{27}$. Quando enviados, os dados eram dúbios ou incompletos, classificando como desanimador o quadro em que se encontrava o serviço de vacinação na província. Como alternativa para reverter a situação, o provedor fez ao presidente a seguinte sugestão: E para melhorar essa sorte de cousas, julgo conveniente serem os professores públicos de primeiras letras obrigados a título de qualquer recompensa a prestarem-se, ficando como inerente no cargo de sua missão o trabalho relativo á vacinação. A vantagem que daqui resulta é grande, serão todos os meninos vacinados, e ao governo poupa-se o inútil trabalho de nomeações, que ou recaem naqueles que por inaptidão não podem bem servir, ou naqueles que não se querem dar ao trabalho de tomar 
interesse sobre a causa pública ${ }^{28}$. Reclamações da mesma natureza repetiam-se em 1873, quando o novo comissário provincial dizia-se impossibilitado de confeccionar os mapas de vacinação, uma vez não ter recebido as informações sobre a aplicação da vacina solicitadas às câmaras ${ }^{29}$.

As dificuldades impostas à promoção da vacina pelas deficiências e pela precariedade existentes na estrutura administrativa eram ampliadas pela displicência e a resistência da população em submeter-se a esse procedimento. Essa postura era avaliada pelas autoridades como decorrência da ignorância popular, que impelia a atitudes irracionais e absurdas, como a das mães da cidade de Leopoldina, que escondiam as filhas debaixo da cama para escapar à vacina ${ }^{30}$. Em Pium-í, a câmara informava haver na cidade um grande prejuízo contra a vacina e que, por mais que se esforçasse em apresentá-la como um dos grandes benefícios da Providência, a população se recusava à inoculação, alegando que estando sãos não hão de procurar doenças, que podem estar com os humores ruins ou que o pus pode ser falso repelindo assim o benefício e ameaçando fugir para as roças ${ }^{31}$. Em 1869, o presidente da província dizia que a fraca propagação da vacina devia-se especialmente ao desleixo indesculpável do povo, que não procura e mesmo desdenha do preservativo da vacina, de que só se lembra na proximidade do perigo, dizendo que nos sertões o povo confundia a vacina com a própria bexiga ${ }^{32}$.

A aversão devotada ao método e a resistência em apresentar-se para a observação e retirada do pus vacínico mobilizava os responsáveis pelo serviço em torno de alternativas a fim de obrigar o povo à prática da vacinação. As sugestões tinham um caráter verdadeiramente policialesco, como o estabelecimento de multas e prisão para quem se recusasse a apresentar-se ou a sua família para a vacinação, a proibição de admissão nas escolas e empregos públicos, a negação de provisões para casamentos ou de estabelecimento de loja ou qualquer outro meio público de vida para quem não se submetesse à vacina - o que, certamente, só haveria de aumentar o pavor da população diante da vacina. No entanto, havia também a preocupação em estimular os responsáveis pela aplicação do preservativo, com o estabelecimento de prêmios aos facultativos na proporção de pessoas vacinadas ou a remuneração deles para que propagassem a vacina pelas freguesias sob as vistas dos juízes de paz.

Um exame detido sobre o histórico da vacina antivariólica durante o século XIX revela que os receios do povo não eram injustificáveis. Era co- mum que a aplicação da vacina não oferecesse resultados práticos, como demonstram inúmeras cartas trocadas entre os comissários vacinadores e o provedor de saúde provincial. Algumas referências indicavam que a aplicação da vacina desencadeava manifestações mais sérias da doença, havendo relatos de vacinadores que afirmavam a instalação de epidemias após a prática. O modo pelo qual a vacina era propagada - de braço a braço - era por sua vez um facilitador na transmissão de outras moléstias, o que não era ignorado pelos responsáveis pela sua aplicação. Por fim, a necessidade do retorno dos vacinados para que se processasse a reinoculação também contribuía para que parte da população descartasse o recurso a esse método preventivo ${ }^{11}$.

Mas se havia resistência à vacina, o mesmo parecia não acontecer em relação à variolização. A prática era frequentemente descrita pelos comissários, que sugeriam uma ligação direta dessa forma de inoculação com algumas ocorrências epidêmicas, como revela o relato do médico responsável pela assistência às vítimas da epidemia de 1874 na povoação do Inficcionado, justificando o incremento da epidemia pela inoculação de vírus varioloso "que geralmente se faz no povo" ${ }^{16}$. A mesma alegação foi feita sobre uma epidemia na vila de Januária, em 1845, sendo a doença explicada pela inoculação que se andou fazendo de bexigentos para sãos, sem se examinar nem conhecer o estado das bexigas que se iam inocular e o dos pacientes. Os resultados tem sido tristíssimos e terríveis, estamos lutando contra uma verdadeira calamidade, que talvez nunca se espalhasse se não fosse o rude enxerto que preservam em praticar $^{33}$. Além de apontar a presença da prática da variolização entre a população da província, tais relatos deixam deduzir que, pelo menos para uma parte da população, o medo não estava na exposição à contaminação visando adquirir proteção contra as bexigas, mas sim à vacina propagada pelas autoridades. Uma forma de entender esse terror à vacina seria encará-lo como expressão do horror que grande parte da população devotava aos próprios médicos e aos seus conhecimentos ainda bem pouco eficazes. Mas esse medo também pode ser revelador de uma distância entre as concepções populares de doença e cura e aquelas propaladas pela medicina oficial - como, por exemplo, as concepções de doença e cura partilhadas pelos descendentes de africanos, discutida por Chalhoub ${ }^{11}$.

Entretanto, é curioso observar que apesar da ênfase dada à indiferença popular à vacinação, a documentação analisada também sugere um for- 
te movimento em direção à vacina quando da ameaça de epidemias. Ao mesmo tempo que os comissários vacinadores reclamavam que o povo não se submetia à aplicação da vacina, a notícia de um caso de varíola na cidade ou nos seus arredores era motivo para que imediatamente encaminhassem solicitações da linfa, informando ser grande a concorrência dos que queriam ser vacinados. Exemplar é a carta encaminhada pelo comissário vacinador de Juiz de Fora, durante a epidemia de 1874, na qual dizia ser impossível determinar a quantidade de pessoas que havia vacinado, pois tão grande era o número dos que o haviam procurado, que apenas me restava transmitir a vacina, não me restando tempo para fazer assentamento, podendo, contudo, calcular-se terem sido vacinados para mais de mil, mil e quatrocentos pessoas $^{34}$. O que parece ser um comportamento contraditório ganha lógica quando analisado no interior da crise epidêmica; afinal, o principal objetivo nesses momentos era a sobrevivência, independentemente dos meios utilizados. Qualquer sugestão que prometesse a cura ou a proteção contra o flagelo era bem-vinda, independentemente do lugar de sua produção.

\section{Considerações finais}

Durante todo o século XIX a varíola foi uma ameaça constante à população mineira e, mesmo sendo uma experiência relativamente frequente, as aparições da doença não deixaram de causar espanto e alterar a vida cotidiana em diversas localidades da província. A existência de métodos que visavam à prevenção da moléstia desde o início daquele século - como a variolização e a vacina não resultou no abrandamento ou no controle mais eficaz dessas manifestações. Os serviços organizados pelo governo imperial visando à difusão da vacina antivariólica funcionaram de modo precário, contribuindo muitas vezes para aumentar o temor diante da vacinação.

A pesquisa documental sobre a história da varíola e da difusão da vacina em Minas Gerais mostrou como os órgãos e autoridades públicas responsáveis pela vacinação atuaram de forma desarticulada e pouco sistemática. Assim, se é possível identificar uma proposta centralizadora nas determinações do governo imperial em torno da prevenção e do controle da varíola, especialmente após a criação do Instituto Vacínico (1846), não havia por parte das autoridades das diversas esferas da administração imperial meios para o cumprimento delas. Além da própria estrutura administrativa, a difusão da vacina era prejudicada pela postura displicente daqueles encarregados por sua aplicação nas diferentes localidades da província e ainda pela relativa descrença que a população devotava ao método, explicada pela desmoralização do próprio serviço como também pelas concepções de doença muitas vezes distintas do que era propalado pelas teorias médicas.

Entretanto, a desarticulação e a ineficiência não foram uma prerrogativa exclusiva do serviço de vacinação. Além dos comissários vacinadores, as autoridades também desconheciam os dados sobre médicos, boticários, cirurgiões, barbeiros e outros agentes de cura que atuavam na província. Do mesmo modo, não havia controle sobre os diplomas e licenças que eram exigidos desses profissionais, revelando que a existência da lei não pressupunha sua observação, inclusive pelo próprio poder público, que era responsável pela fiscalização desses profissionais. Por fim, se na base do serviço montado pelo Estado a aplicação da vacina dependia da boa vontade dos comissários paroquiais, o socorro e a atenção aos doentes e pobres da província durante o período imperial também se apoiavam no concurso dos particulares e das almas humanitárias. 


\section{Colaboradores}

AJT Silveira e RC Marques participaram igualmente de todas as etapas da elaboração do artigo.

\section{Agradecimentos}

Este artigo é resultado parcial do trabalho de pesquisa desenvolvido pelo projeto A História da Varíola na Província de Minas Gerais - Século XIX, apoiado pelo Conselho Nacional de Pesquisa (CNPq) e pela Fundação de Amparo à Pesquisa de Minas Gerais (Fapemig). Os relatórios e mensagens dos presidentes da província, cobrindo o período de 1837 a 1930, também estão disponíveis em http://www.crl.edu/pt-br/brazil/provincial/minas_gerais.

\section{Referências}

1. Dobson M. Disease: the extraordinary stories behind history's deadliest killers. London: Quercus; 2007.

2. Crosby AW. Smallpox. In: Kenneth K, editor. The Cambridge world history of human disease. Cambridge: Cambrige University Press; 1999. p. 1009-1010.

3. Crosby AW. Imperialismo ecológico: a expansão biológica da Europa: 900-1900. São Paulo: Companhia das Letras; 2000.

4. Sournia JC, Rufie J. As epidemias na história do homem. Lisboa: Edições 70; 1976.

5. McNeill WH. Plagues and peoples. New York: Anchor Books; 1971.

6. Ribeiro L. Medicina no Brasil Colonial. Rio de Janeiro: s.l.; 1971.

7. Salles P. História da medicina no Brasil. 2a ed. Belo Horizonte: Coopmed; 2004.

8. Santos Filho LS. História geral da medicina brasileira. v. 2. São Paulo: Hucitec/EdUSP; 1991.

9. Relatório que à Assembléia Provincial de Minas Gerais apresentou no ato da abertura da seção ordinária de 1865 o Desembargador Pedro de Alcântara Cerqueira Leite, presidente da mesma província. Ouro Preto: Tipografia de Minas Gerais; 1865.

10. Fernandes TM. A vacina antivariólica: ciência, técnica e o poder dos homens - 1808-1920. Rio de Janeiro: Editora Fiocruz; 1999.

11. Chalhoub S. Cidade febril: cortiços e epidemias na corte imperial. São Paulo: Companhia das Letras; 1996.

12. Fala dirigida á Assembléia Legislativa Provincial de Minas Gerais na sessão ordinária do ano de 1847 pelo presidente da Província, Quintiliano José da Silva. Ouro Preto: Tipografia Imparcial de B. X. Pinto de Sousa; 1847.

13. Relatório que à Assembléia Legislativa Provincial de Minas Gerais apresentou no ato de abertura da Seção Ordinária de 1874 o Vice-Presidente Francisco Leite da Costa Belém. Ouro Preto: Tipografia de J. F. de Paula Castro; 1874.

14. Relatório que o Ilm., Exm. Sr. Dr. Francisco Leite da Costa Belém, 2 Vice-Presidente da Província de Minas Gerais apresentou, no ato de passar-lhe a Administração da mesma Província, ao Exm Sr Desembargador João Antonio de Araújo Freitas Henriques, a 6 de março de 1875. Ouro Preto: Tipografia de J. F. de Paula Castro; 1875.

15. Minas Gerais. Arquivo Público Mineiro, Seção Provincial, Fundo Secretaria do Governo, SP. SG.259, doc. 257.

16. Minas Gerais. Arquivo Público Mineiro, Seção Provincial, Fundo Presidência da Província, SP. PP.26, cx. 04 , doc. 03 .

17. Minas Gerais. Arquivo Público Mineiro, Seção Provincial, Fundo Presidência da Província, SP. PP26, cx. 06 , doc. 42 .

18. Relatório que o Ilm., Exm. Sr. Dr. Joaquim Delfino Ribeiro da Luz, Vice-Presidente da Província entregou ao Ilm., Sr. Conselheiro Carlos Carneiro de Campos em o dia 6 de abril de 1859 no momento de seguir para a Vila de Lavras a fim de assistir às arrematações da Estrada do Passa Vinte. Ouro Preto: Tipografia Provincial; 1859. 
19. Arquivo Histórico Ultramarino, cx.178, doc.14, rolo 164, gav. F4.

20. Brasil. Lei do $1^{\circ}$ de outubro de 1828 . Dá nova forma às Câmaras Municipais, marca suas atribuições e o processo para a sua eleição e dos Juizes de Paz. Coleção de Leis do Império do Brasil de 1828. Rio de Janeiro: Tipografia Nacional; 1878 [acesso 2010 mar 05]. p. 74-89. Disponível em: http://www.camara. gov.br/ Internet/InfDoc/conteudo/colecoes/Legislacao/ Legimp-K_18.pdf

21. Lopes MB. Vacina antivariólica. In: Gonçalves AL, Oliveira RP, organizadores. Termo de Mariana: história e documentação. v. II. Mariana, MG: Imprensa Universitária da Universidade Federal de Ouro Preto; 2004. p. 161-167.

22. Brasil. Decreto $n^{\circ} 464$, de 17 de agosto de 1846. Manda executar o Regulamento do Instituto Vacínico do Império. Rio de Janeiro: Tipografia Nacional, 1847. Coleção das Leis do Império do Brasil [acesso 2010, mar 5]. p. 86-98. Disponível em: http://www. camara.gov.br/Internet/InfDoc/conteudo/colecoes/ Legislacao/legimp-32/Legimp-32_18.pdf

23. Minas Gerais. Arquivo Público Mineiro, Seção Provincial, Fundo Presidência da Província, SP.PP.26, cx.03, doc.06.47.

24. Minas Gerais. Arquivo Público Mineiro, Seção Provincial, Fundo Presidência da Província, SP.PP.26, cx.01, doc. 89 .

25. Minas Gerais. Arquivo Público Mineiro, Seção Provincial, Fundo Presidência da Província, SP.PP.26, cx.02, doc. 13.52 .

26. Relatório apresentado à Assembléia Legislativa Provincial de Minas Gerais na Sessão Ordinária de 1869 pelo Presidente da mesma Província, Dr. José Maria Corrêa de Sá e Benevides. Rio de Janeiro: Tip. Universal de Laemmert; 1870 (Anexo 1).
27. Minas Gerais. Arquivo Público Mineiro, Seção Provincial, Fundo Presidência da Província, SP.PP.26, cx.02, doc. 45 .

28. Relatório que á Assembléia Legislativa Provincial de Minas Gerais apresentou no ato da abertura da Sessão Ordinária de 1870 o Vice-Presidente, Dr. Agostinho José Ferreira Bretas. Ouro Preto: Tip. Provincial; 1870 (Apenso 4).

29. Minas Gerais. Arquivo Público Mineiro, Seção Provincial, Fundo Presidência da Província, SP.PP.26, cx.03, doc. 31 .

30. Minas Gerais. Arquivo Público Mineiro, Seção Provincial, Fundo Presidência da Província, PP1/26, cx.02, doc.14.39.

31. Minas Gerais. Arquivo Público Mineiro, Seção Provincial, Fundo Presidência da Província, SS.PP, cx.02, doc. 14.46

32. Relatório que Ilm., Exm. Sr. Dr. José Maria Correa de Sá e Benevides, Presidente da Provincia de Minas Gerais, apresentou no ato de passar a administração, em 14 de maio de 1869 ao Dr. Domingos de Andrade Figueira. Ouro Preto: Tipografia de J. F. de Paula Castro; 1869.

33. Minas Gerais. Arquivo Público Mineiro, Seção Provincial, Fundo Presidência da Província, SP.PP.26, cx. 01 , doc. 80 .

34. Minas Gerais. Arquivo Público Mineiro, Seção Provincial, Fundo Presidência da Província, SP.PP.26, cx.04, doc.13.

Artigo apresentado em 5/4/2010

Aprovado em 24/6/2010

Versão final apresentada em 7/7/2010 